\title{
Analisis Wilayah Pengembangan Sapi Potong dalam Mendukung Swasembada Daging di Jawa Tengah
}

\section{Analysis Development Regional of Cattle Beef in Support Meat Self-Sufficiency in Central Java}

\author{
Mukson, W. Roessali dan H. Setiyawan \\ Fakultas Peternakan dan Pertanian Universitas Diponegoro Semarang \\ e-mail : mukson.fapetundip@gmail.com \\ (Diterima: 13 November 2013; Disetujui: 14 Februari 2014)
}

\begin{abstract}
ABSTRAK
Penelitian bertujuan menganalisis potensi wilayah untuk pengembangan sapi potong dan faktor-faktor yang mempengaruhi pengembangan sapi potong dalam mendukung swasembada daging di Jawa Tengah. Penelitian dilakukan dengan menganalisis data sekunder bersumber dari Dinas Peternakan dan Kesehatan Hewan Provinsi Jawa Tengah dan Badan Pusat Statistik Provinsi Jawa Tengah (2013). Data dianalisis secara deskriptip dan statistik. Analisis potensi wilayah menggunakan parameter location quotient (LQ) dan faktor-faktor pengembangan sapi potong dianalisis dengan model regresi linier berganda, dengan faktor dependen $(\mathrm{Y})$ produksi daging sapi dan variabel independen $(\mathrm{X})$ dari berturut-turut adalah populasi sapi potong, produksi daging total Jawa Tengah, jumlah penduduk, pengeluaran ternak sapi potong ke luar daerah, dan kapasitas rumah potong hewan (RPH). Hasil penelitian menunjukkan bahwa nilai LQ berdasarkan kawasan pengembangan sapi potong (kawasan I sd.V) rata-rata sebesar 1,32 (sektor basis sapi potong). Rasio produksi daging sapi dengan tingkat kebutuhan riil penduduk mempunyai Indeks Subsistensi (IS) sebesar 1,27, yang berarti produksi daging sapi Jawa Tengah sudah berlebih. Analisis faktor-faktor pengembangan wilayah sapi potong secara bersama-sama sangat nyata $(\mathrm{P}<0,01)$ dipengaruhi oleh semua variable indipenden (nilai $\left.\mathrm{R}^{2}=0,584\right)$. Hasil ini menunjukkan bahwa dalam mendukung swasembada daging perlu terus diupayakan peningkatan populasi sapi potong, peningkatan produksi daging selain ternak sapi, pengendalian jumlah penduduk, pengeluaran ternak sapi hidup ke lain daerah dan kapasitas pemotongan di RPH yang perlu terus dipantau dan dijaga kesinambungannya.
\end{abstract}

Kata kunci : potensi, pengembangan, swasembada, daging, sapi potong

\begin{abstract}
This study aimed to analyze the regional potency for the development of cattle beef and influencing factors of cattle beef development that support meat self-sufficiency in Central Java. The study was conducted by analyzing secondary data (2008 - 2012) from the Department of Animal Husbandry and Animal Health Central Java, Central Bureau of Statistics Central Java Province. Data were analyzed with descriptive statistics. The regional potency being analyzed using the parameter location quotient $(L Q)$ and cattle beef development factors being analyzed using multiple linear regression; with beef production as the dependent variable $(Y)$ and the independent variables consisted of beef cattle population, Central Java total meat production, total population, the number of cattle moving out of the area, and the capacity of slaughter house. The results showed that the value of $L Q$ based on cattle beef development region (region I to V) by average of 1.32 (cattle beef sector basis). The beef production ratio with the real necessity of the population have a subsistence index (IS) of 1.27, which means Central Java beef production already been in excessive number. Analysis of regional development factors of beef all together significantly affected $(P<0.01)$ by all independent variables $\left(R^{2}=0.584\right)$. These results indicate
\end{abstract}


that the support against meat self-sufficiency should continue to be pursued by the efforts in increasing meat production aside of beef cattle, controlling population, evaluating and calculating live export moving out of the area and monitoring the sustainability of cattle slaughter house capacity.

Keywords : potency, development, self-sufficiency in meat, cattle beef

\section{PENDAHULUAN}

Pembangunan sub sektor peternakan terus dituntut peran sertanya dalam perekonomian nasional maupun regional, melalui pembentukan Produk Domestik Regional Bruto (PDRB), sumber devisa melalui ekspor, penyediaan bahan pangan dan bahan baku industri, pengentasan kemiskinan melalui penyediaan lapangan kerja dan peningkatan pendapatan masyarakat. Peran penting dan strategis ini sejalan dengan program revitalisasi pertanian yang menempatkan kembali arti penting pertanian (peternakan) secara proporsional yang antara lain guna mendukung kecukupan dan ketersediaan akan pangan asal ternak (daging sapi).

Kebutuhan daging asal ternak sapi terus meningkat sejalan dengan peningkatan jumlah penduduk, kesadaran akan pangan bergizi dan pertumbuhan ekonomi masyarakat. Peningkatan ini dapat dilihat dari produksi daging sapi di Jawa Tengah yang terus meningkat dari tahun 2008 sebesar $45.755 .802 \mathrm{~kg}$ menjadi $60.892 .739 \mathrm{~kg}$ (tahun 2012), atau selama 5 tahun rata-rata meningkat sebesar $7,61 \%$. Kondisi permintaan (demand) yang terus meningkat dituntut adanya langkah-langkah strategis agar penyediaan daging bisa terpenuhi. Kaitan dengan permintaan yang terus meningkat, saat ini pemerintah Indonesia melakukan impor sapi. Kondisi ini tidak menguntungkan apabila ditinjau dari aspek pengembangan usaha peternakan maupun kebutuhan devisa untuk impor. Oleh karena itu, maka perlu terus mendorong berbagai sumber daya (modal, manusia, teknologi dan sumber daya wilayah/lahan) agar terus mampu memberikan perannya guna peningkatan populasi, produksi dan produktivitas sapi potong. Menurut Diwyanto dan Priyanti (2006) bahwa tantangan utama dalam pengembangan usaha peterna- kan adalah dicanangkannya program revitalisasi pertanian dan ketahanan pangan yang akan meningkatkan produktivitas pertanian (termasuk peternakan) melalui optimalisasi sumberdaya lokal. Untuk itu perlu ada upaya yang strategis dan berkesinambungan utamanya dalam pengelolaan usaha sapi potong agar dicapai produktivitas dan efisiensi yang tinggi.

Provinsi Jawa Tengah merupakan salah satu provinsi di Pulau Jawa, mempunyai potensi besar untuk pengembangan sapi potong. Pengembangan populasi dan produktivitas ternak sapi sangat penting, utamanya dalam rangka penyediaan ternak sapi/daging sapi, baik untuk kebutuhan regional maupun nasional, khusunya DKI dan Jawa Barat. Berdasarkan pembagian wilayah, Jawa Tengah memiliki basis dan keunggulan wilayah yang potensial untuk pengembangan sapi potong. Hendarto (2002) mengatakan bahwa suatu wilayah dapat dibedakan menjadi sektor basis (basic sector), dan sektor non basis (non basic sector). Wilayah basis sektor dapat berfungsi untuk keperluan pertukaran (to exchange) dan dapat dianalisis dengan melihat perbandingan relatif kegiatan usaha suatu wilayah dengan wilayah lain yang lebih luas. Menurut Kurnianto (2006) dalam mengembangkan kawasan maka perlu diperhatikan potensi dan kesesuaian agroekosistem dan efisiensi penggunaan sumberdaya. Keberadaan wilayah potensial (sektor basis) sapi potong ini diharapkan akan mampu mensuplai kebutuhan ternak, sehingga perlu dianalisis potensinya serta faktor-faktor apa saja yang mempengaruhi pengembangan sapi potong dalam upaya mendukung swasembada daging.

\section{METODE}

Penelitian tentang analisis wilayah pengembangan sapi potong di Jawa Tengah 
ditentukan secara purposive sampling, berdasarkan potensi yang dimiliki oleh masingmasing wilayah. Ada lima kawasan potensial yang dianalisis, yaitu : 1) Kawasan bagian Tenggara, terdiri dari 6 Kabupaten, yaitu Boyolali, Klaten, Sragen, Sukoharjo, Wonogiri dan Karanganyar, 2) Kawasan bagian Barat, terdiri dari 2 Kabupaten, yaitu Brebes dan Tegal, 3) Kawasan bagian Timur, terdiri dari 5 Kabupaten, yaitu : Jepara, Rembang, Grobogan, Pati dan Blora, 4) Kawasan bagian Tengah, terdiri dari 4 Kabupaten, yaitu : Semarang, Magelang, Temanggung dan Wonosobo dan 5) Kawasan bagian Barat Daya, terdiri dari 4 Kabupaten, yaitu : Kebumen, Purbalingga, Banjarnegara dan Banyumas. Penelitian dilakukan dengan menganalisis data sekunder dari instansi terkait, seperti Dinas Peternakan dan Kesehatan Hewan Provinsi Jawa Tengah dan Badan Pusat Statistik dan sumber lain yang relevan. Data dianalisis secara deskriptif dan secara statistik. Analisis potensi pengembangan sapi potong digunakan analisis LQ (Location Quotient) berdasarkan indikator populasi ternak sesuai petunjuk Hendarto (2002) dan Amalia (2007) sebagai berikut :

$$
\mathrm{LQ}=\frac{\sum P S P T k: \sum P S P T j}{\sum P T B K k: \sum P T B K j}
$$

Keterangan :

$\Sigma$ PSPTk $=$ Jumlah populasi sapi potong di wilayah masing-masing Kabupaten

$\Sigma$ PSPTj $=$ Jumlah populasi sapi potong di Jawa Tengah

$\Sigma$ PTBKk $=$ Jumlah populasi ternak besar dan kecil di wilayah masing-masing Kabupaten

$\Sigma$ PTBKj $=$ Jumlah populasi ternak besar dan kecil di Jawa Tengah

Kriteria LQ :

- Apabila LQ > 1 : sektor basis/potensial

- Apabila $L Q=1:$ seimbang/cukup potensial

- Apabila LQ < 1 : nonbasis/kurang potensial

Untuk mengetahui faktor-faktor yang mempengaruhi pengembangan sapi potong dalam mendukung swasembada daging di Jawa Tengah, dianalisis dengan menggunakan model statistik regresi linier berganda sesuai petunjuk Ghozali (2005), sebagai berikut :

$Y: a+b_{1} x_{1}+b_{2} x_{2}+b_{3} x_{3}+b_{4} x_{4}+b_{5} x_{5}+e$, dimana :

$\mathrm{Y}=$ Produksi daging sapi $(\mathrm{kg} / \mathrm{th})$

$\mathrm{a}=$ Konstanta

$\mathrm{b}=$ Koefisien regresi

$\mathrm{x}_{1}=$ Populasi sapi potong (ekor)

$\mathrm{x}_{2}=$ Produksi daging total $(\mathrm{kg} / \mathrm{th})$

$\mathrm{x}_{3}=$ Jumlah penduduk (jiwa)

$\mathrm{x}_{4}=$ Pengeluaran ternak sapi ke luar daerah Jawa Tengah (ekor/tahun)

$\mathrm{x}_{5}=$ Kapasitas pemotongan ternak sapi di RPH (ekor/hari)

$\mathrm{e}=$ Simpangan stokastik

Uji statistik dengan uji $F$ digunakan untuk menguji model regresi linier berganda dengan taraf signifikan 5\%. Sedangkan Uji t digunakan untuk mengetahui secara parsial pengaruh variabel independen (populasi sapi potong, produksi daging total, jumlah penduduk, pengeluaran ternak sapi ke luar daerah dan kapasitas pemotongan ternak di RPH) terhadap variabel dependen (produksi daging sapi).

\section{HASIL DAN PEMBAHASAN}

\section{Gambaran Umum Usaha Ternak Sapi Potong di Jawa Tengah}

Propinsi Jawa Tengah merupakan salah satu propinsi di Pulau Jawa sebagai pensuplai dan penyangga kebutuhan ternak serta daging untuk wilayah Jawa Barat dan DKI. Jumlah populasi sapi potong pada tahun 2012 sebanyak 2.051.407 ekor, dengan jumlah rumah tangga pemilik sebanyak 932.696 orang, atau masing-masing rumah tangga memelihara kurang lebih sebanyak 2,19 ekor. Jumlah ini masih relatif kecil, mengingat berbagai faktor keterbatasan yang ada pada peternak, seperti permodalan, ketrampilan usaha, dan motif usaha yang rata-rata masih bersifat sambilan. Keterbatasan modal yang ada pada peternak saat ini mulai terus ditingkatkan dengan berbagai program pengembangan sapi potong, yaitu melalui kredit ketahanan pangan dan energi (KKPE), KUPS (kredit usaha pembibitan sapi), Sarjana Membangun Desa (SMD) dan skim program pengembangan lain-lain. 
Perkembangan sapi potong di Jawa Tengah terus mengalami peningkatan, selama 5 tahun (2008-2012) rata-rata tumbuh sebesar $9,55 \%$, dari sebanyak 1.442 .033 ekor (2008) menjadi 2.051.407 ekor (2012) (Dinas Peternakan dan Kesehatan Hewan Provinsi Jawa Tengah, 2013). Perkembangan populasi sapi potong dan produksi daging sapi di Jawa Tengah dapat dilihat pada Tabel 1 .

Tabel 1. Perkembangan populasi sapi potong dan produksi daging sapi di Jawa Tengah

\begin{tabular}{|c|c|c|c|}
\hline No. & Tahun & $\begin{array}{c}\text { Populasi } \\
\text { (ekor) }\end{array}$ & $\begin{array}{l}\text { Produksi daging } \\
\text { sapi }(\mathrm{kg})\end{array}$ \\
\hline 1. & 2008 & 1.442 .033 & 45.735 .802 \\
\hline 2. & 2009 & 1.525 .250 & 48.340 .155 \\
\hline 3. & 2010 & 1.554 .458 & 51.001 .374 \\
\hline 4. & 2011 & 1.937 .551 & 60.322 .069 \\
\hline 5. & 2012 & 2.051 .407 & 60.892 .739 \\
\hline
\end{tabular}

Sumber : Dinas Peternakan dan Kesehatan Hewan Provinsi Jawa Tengah (2013)

Produksi daging sapi di Jawa Tengah juga terus meningkat seiring dengan kesadaran masyarakat akan pentingnya makanan yang lebih bergizi dan terpenuhinya kecukupan pangan hewani asal ternak. Berdasarkan sumber pangan asal daging, daging sapi menempati urutan ke dua setelah ayam ras, dan rata-rata nasional konsumsi daging sapi sebesar $1,44 \mathrm{~kg} / \mathrm{kapita} / \mathrm{tahun}$, sedangkan ayam ras paling tinggi, yaitu $3,514 \mathrm{~kg} / \mathrm{kapita} / \mathrm{tahun}$ (Dirjen Peternakan dan Kesehatan Hewan, 2011). Produksi daging sapi di Jawa Tengah pada tahun 2012 sebanyak $60.892 .739 \mathrm{~kg}$. Pertumbuhan produksi daging selama 5 tahun (2008-2012) sebesar 7,61\%, dari 45.735 .802 $\mathrm{kg}$ (2008) meningkat menjadi 60.892 .739 (2012).

Berdasarkan Indeks Subsistensi (IS) yaitu rasio antara produksi dengan kebutuhan penduduk, dengan mengacu kebutuhan penduduk pada tingkat nasional, yaitu sebesar 1,44 $\mathrm{kg} / \mathrm{kapita} / \mathrm{tahun}$, dan estimasi jumlah penduduk Jawa Tengah tahun 2012 sebesar
33.270.207 jiwa (Jawa Tengah dalam Angka, 2013), maka Jawa Tengah sudah mengalami surplus produksi daging sapi, atau berdasarkan perhitungan IS sebesar 127,10\%; yang berarti ada kelebihan sebanyak 27,10\%. Kelebihan ini dapat digunakan untuk memenuhi permintaan dan kebutuhan penduduk diluar Jawa Tengah. Kondisi ini juga menunjukkan bahwa Provinsi Jawa Tengah, berdasarkan indeks IS sudah terlampui baik IS aktual (90\% - 110\%) maupun IS ideal (>110\%) (Aritonang, 2000).

\section{Analisis Wilayah Pengembangan Sapi Potong di Jawa Tengah}

Gambaran potensi wilayah untuk pengembangan sapi potong dapat dianalisis dengan parameter nilai LQ. Hasil penelitian menunjukkan bahwa nilai LQ berdasarkan kawasan pengembangan yang terdiri dari 5 Kawasan dapat dilihat pada Tabel 2. Berdasarkan Tabel 2 dapat dilihat bahwa rata-rata nilai LQ untuk 4 kawasan sangat potensial untuk pengembangan sapi potong, yaitu Kawasan Tenggara, Kawasan Timur, Kawasan Tengah, dan Kawasan Barat Daya, sedangkan satu kawasan yang masih kurang potensial adalah Kawasan Barat utamanya Kabupaten Tegal. Hasil ini juga menunjukkan bahwa terdapat potensi ekonomi sapi potong yang dapat dikembangkan untuk mendukung pertumbuhan ekonomi daerah setempat. Hasil penelitian Mukson et al. (2006) dengan mengambil sampel 17 Kabupaten di Jawa Tengah menunjukkan nilai rata-rata LQ berdasarkan PDRB (Produk Domestik Regional Bruto) sub sektor peternakan sebesar 1,33. Kondisi ini berarti Propinsi Jawa Tengah merupakan daerah yang potensial untuk pengembangan peternakan. Disamping itu, berdasarkan carrying capacity masih banyak wilayah-wilayah yang masih kurang ternak (-), dan untuk wilayah bagian Tenggara masih banyak Kabupaten-kabupaten yang terlalu padat ternak (+) dibanding ketersediaan pakan, sehingga perlu adanya teknologi pengolahan pakan terutama untuk mengatasi kesulitan pada musim kemarau. 
Tabel 2. Potensi sektor basis berdasarkan nilai LQ populasi sapi potong dan Carrying Capacity di kawasan pengembangan di Jawa Tengah

\begin{tabular}{|c|c|c|c|}
\hline $\begin{array}{l}\mathrm{No} \\
.\end{array}$ & $\begin{array}{c}\text { Kawasan } \\
\text { Pengembangan }\end{array}$ & $\begin{array}{c}\text { Nilai } \\
\text { LQ }\end{array}$ & $\begin{array}{c}\text { Carrying } \\
\text { Capacity } \\
\text { (AU) }\end{array}$ \\
\hline \multicolumn{4}{|c|}{ 1. Kawasan Tenggara } \\
\hline & 1.1. Kab. Boyolali & 1,03 & + \\
\hline & 1.2. Kab. Klaten & 1,75 & + \\
\hline & 1.3. Kab. Sragen & 1,93 & + \\
\hline & 1.4. Kab.Sukoharjo & 1,62 & + \\
\hline & 1.5. Kab. Wonogiri & 1,54 & + \\
\hline & $\begin{array}{l}\text { 1.6. Kab. } \\
\text { Karanganyar }\end{array}$ & 1,65 & - \\
\hline & Rata-rata & 1,59 & + \\
\hline \multicolumn{4}{|c|}{ 2. Kawasan Barat } \\
\hline & 2.1.Kab. Brebes & 1,02 & - \\
\hline & 2.2. Kab. Tegal & 0,51 & - \\
\hline & Rata-rata & 0,77 & - \\
\hline \multicolumn{4}{|c|}{ 3. Kawasan Timur } \\
\hline & 3.1. Kab. Jepara & 1,69 & - \\
\hline & 3.2. Kab. Rembang & 1,79 & + \\
\hline & 3.3. Kab. Grobogan & 2,04 & - \\
\hline & 3.4. Kab. Pati & 1,86 & + \\
\hline & 3.5. Kab. Blora & 2,12 & - \\
\hline & Rata-rata & 1,90 & - \\
\hline \multicolumn{4}{|c|}{ 4. Kawasan Tengah } \\
\hline & 4.1.Kab. Semarang & 0,74 & - \\
\hline & 4.2.Kab. Magelang & 1,55 & - \\
\hline & 4.3.Kab. Temanggung & 1,09 & - \\
\hline & 4.4. Kab. Wonosobo & 0,93 & - \\
\hline & Rata-rata & 1,08 & - \\
\hline \multicolumn{4}{|c|}{ 5. Kawasan Barat Daya } \\
\hline & 5.1. Kab. Kebumen & 1,30 & + \\
\hline & 5.2. Kab. Purbalingga & 0,51 & - \\
\hline & 5.3.Kab. Banjarnegara & 2,60 & - \\
\hline & 5.4. Kab. Banyumas & 0,69 & - \\
\hline & Rata-rata & 1,27 & - \\
\hline
\end{tabular}

Analisis Faktor-faktor yang Mempengaruhi Pengembangan Sapi Potong dalam Mendukung Swasembada Daging di Jawa Tengah

Penelitian analisis wilayah untuk pengembangan sapi potong dalam mendukung swasembada daging di Jawa Tengah dianalisis menggunakan model regresi linier berganda, dengan variabel dependen $\mathrm{Y}$ (produksi daging sapi) dan variabel independen $\mathrm{X}_{1}$ (populasi sapi potong), $\mathrm{X}_{2}$ (produksi daging total), $\mathrm{X}_{3}$ (jumlah penduduk), $\mathrm{X}_{4}$ (pengeluaran ternak sapi potong ke luar daerah), dan $\mathrm{X}_{5}$ (kapasitas pemotongan hewan di RPH) menunjukkan bahwa variabel independen secara bersama-sama sangat nyata $(\mathrm{P}<0,01)$ mempengaruhi produksi daging sapi.

Tabel 3. Faktor-faktor yang mempengaruhi pengembangan sapi potong dalam mendukung swasembada daging di Jawa Tengah

\begin{tabular}{|c|c|c|c|}
\hline No. & $\begin{array}{c}\text { Variabel } \\
\text { pengembangan }\end{array}$ & $\begin{array}{c}\text { Koefisien } \\
\text { Regresi }\end{array}$ & Sign. \\
\hline 1. & Konstanta & $-218157,190$ & \\
\hline 2. & $\begin{array}{l}\text { Populasi sapi } \\
\text { potong }\left(\mathrm{X}_{1}\right)\end{array}$ & 8,187 & $0,069 *)$ \\
\hline 3. & $\begin{array}{l}\text { Produksi } \\
\text { daging total } \\
\left(\mathrm{X}_{2}\right)\end{array}$ & 0,113 & 0,128 \\
\hline 4. & $\begin{array}{l}\text { Jumlah } \\
\text { penduduk }\left(\mathrm{X}_{3}\right)\end{array}$ & $-0,290$ & 0,663 \\
\hline 5. & $\begin{array}{l}\text { Pengeluaran } \\
\text { sapi potong ke } \\
\text { luar daerah } \\
\text { Jawa Tengah } \\
\left(\mathrm{X}_{4}\right)\end{array}$ & 39,140 & 0,296 \\
\hline 6. & $\begin{array}{l}\text { Kapasitas } \\
\text { pemotongan } \\
\text { ternak di RPH } \\
\left(\mathrm{X}_{5}\right)\end{array}$ & 37134,627 & $0,00 * * *)$ \\
\hline & F hit. & 8,148 & $0,001 * *)$ \\
\hline & $\mathrm{R}^{2}$ & 0,584 & \\
\hline
\end{tabular}

Hasil ini menunjukkan bahwa populasi sapi potong perlu terus dijaga pertumbuhannya, serta potensi sumberdaya ternak lain sebagai sumber pangan substitusi, pengendalian peningkatan jumlah penduduk, permintaan ternak dan fasilitas pendukung pada proses pasca panen perlu diperhatikan. Hasil penelitian tentang faktor-faktor pengembangan sapi potong selengkapnya dapat dilihat pada Tabel 3. Tabel 3 menunjukkan bahwa secara parsial jumlah populasi sapi potong dan kapasitas pemotongan ternak di RPH mempunyai pengaruh positif terhadap peningkatan penyediaan daging. Hal ini perlu terus diupayakan strategi pengembangan sapi potong di 
Jawa Tengah dalam upaya terus menjaga ketahanan pangan dan swasembada daging sapi potong. Beberapa langkah yang perlu diupayakan adalah perbaikan manajemen usaha pada peternakan rakyat utamanya pada pemberian pakan yang lebih baik, perbaikan mutu genetik dan penanganan inseminasi buatan yang lebih mampu menekan angka service per conseption sehingga diharapkan produktivitas dan populasi ternak terus meningkat. Hasil penelitian Soemarjono et al. (2008) di Kabupaten Blora, menunjukkan bahwa penerapan kebijakan pengembangan sapi potong dapat dilakukan melalui jalur peningkatan potensi lahan, potensi sumberdaya manusia, dan pakan dalam sistem pertanian.

Berdasarkan Tabel 3 dapat dilihat bahwa peningkatan populasi satu satuan ternak maka akan mendorong peningkatan produksi daging sebesar 8,187 satuan, dan peningkatan kapasitas pemotongan di RPH akan mampu meningkatkan produksi daging sebesar $37.134,627 \mathrm{~kg}$ daging/tahun. Berdasarkan Tabel 3 juga dapat dilihat bahwa nilai koefisien determinasi $\left(\mathrm{R}^{2}\right)$ sebesar 0,584 , hal ini menunjukkkan bahwa tingkat produksi daging sapi di Jawa Tengah dapat dijelaskan oleh variabel independen $\mathrm{X}_{1}, \mathrm{X}_{2}, \mathrm{X}_{3}, \mathrm{X}_{4}$ dan

$\mathrm{X}_{5}$ secara bersama-sama sebanyak $58,4 \%$, sedangkan sisanya sebanyak $41,6 \%$ dipengaruhi oleh faktor lain diluar model. Hasil penelitian ini menunjukkan bahwa produksi daging sapi di Jawa Tengah perlu diperhatikan tingkat populasi sapi potong, dengan didukung penyediaan pakan yang cukup, manajemen usaha dan zooteknis pemeliharaan yang memadai.

\section{KESIMPULAN}

Pengembangan usaha sapi potong di Jawa Tengah berdasarkan wilayah/kawasan yang ada sangat potensial untuk dikembangkan. Produksi daging sapi sudah mencukupi kebutuhan riil penduduk Jawa Tengah dengan indeks subsistensi sebesar 1,27. Secara bersama-sama faktor populasi sapi potong, produksi daging total, jumlah penduduk, pengeluaran ternak sapi potong ke luar daerah dan kapasitas pemotongan hewan di RPH sangat nyata mempengaruhi produksi daging sapi. Hasil ini menunjukkkan bahwa peningkatan tingkat produksi daging sapi perlu terus mendorong peningkatan populasi dan produktivitas ternak serta infrastuktur pendukung pengembangan usaha ternak.

\section{DAFTAR PUSTAKA}

Amalia, I. 2007. Ekonomi Pembangunan Edisi I. Cetakan ke I. Penerbit Graha Ilmu, Jakarta.

Aritonang, I. 2000. Krisis Ekonomi Akar Masalah Gizi. Penerbit Media Pressindo, Yogyakarta.

Badan Pusat Statistik Provinsi Jawa Tengah. 2013. Jawa Tengah dalam angka 2013. Badan Pusat Provinsi Jawa Tengah, Semarang.

Dinas Peternakan dan Kesehatan Hewan Propinsi Jawa Tengah. 2013. Statistik peternakan tahun 2013. Dinas Peternakan dan Kesehatan Hewan Provinsi Jawa Tengah, Ungaran.

Direktorat Jenderal Peternakan dan Kesehatan Hewan. 2011. Statistik peternakan dan kesehatan hewan 2011. Direktorat Jenderal Peternakan dan Kesehatan Hewan, Jakarta.

Diwyanto, K dan A. Priyanti. 2006. Kondisi, potensi dan permasalahan agribisnis peternakan dalam mendukung ketahanan pangan. Prosiding Seminar Nasional Pemberdayaan Masyarakat Peternakan di Bidang Agribisnis untuk Mendukung Ketahanan Pangan. Fakultas Peternakan UNDIP, Semarang, 3 Agustus 2006.

Ghozali. 2005. Aplikasi Analisis Multivariate dengan Program SPSS. Badan Penerbit Universitas Diponegoro, Semarang.

Hendarto, R. M. 2002. Analisis Potensi Daerah dalam Pembangunan Ekonomi. Fakultas Ekonomi Universitas Diponegoro, Semarang. 
Kurnianto, E. 2006. Peran Perguruan Tinggi dalam pengembangan perbibitan ternak di Indonesia. Seminar Nasional Prospek Pengembangan Perbibitan Ternak Menuju Swasembada Pangan Hewani Asal Ternak. Fakultas Peternakan UNDIP Semarang. Tanggal 11 Oktober 2006.

Mukson, E. Prasetyo, B. M. Setiawan dan H. Setiyawan. 2006. Analisis faktor-faktor yang mempengaruhi pengembangan peternakan di Jawa Tengah. J. Sosial Ekonomi Peternakan. Fakultas Peternakan Universitas Diponegoro, Semarang. Vol 1 (1) $31-38$.

Sumarjono, D., Sumarsono dan Sutiyono. 2008. Penerapan analisis jalur untuk pengembangan sapi potong berbasis potensi lahan usaha tani di Kabupaten Blora, Jawa Tengah. J. Pengembangan Peternakan Tropis. Fakultas Peternakan UNDIP. Vol. 33 No. 3 : 231-237. 